\title{
MENINGKATKAN MUTU PENDIDIKAN MELALUI SUPERVISI PENDIDIKAN DALAM PENGEMBANGAN SARANA DAN PRASARANA UNTUK MENCAPAI KUALITAS PENDIDIKAN
}

\author{
ELVI YUSRINA
}

E-mail : elviyusrina@gmail.com

\begin{abstract}
ABSTRAK
Kualitas pendidikan di Indonesia termasuk belum menunjukkan kemajuan yang signifikan, mungkin juga karena kegiatan pembelajaran belum optimal dan pengelolaan lembaga pendidikan yang kurang profesional. Untuk mengatasi masalah tersebut, beberapa solusi ditawarkan. Salah satunya adalah bahwa pelaksanaan pengawasan harus dilakukan secara optimal, prosedural, dan profesional. Dalam hal ini, pengawasan mengambil peran sebagai, (1) supervisi akademik: mitra guru, inovator, dan perintis, konsultan pengajaran dan pendidikan, penasihat guru, dan motivator, (2) supervisi manajerial: konseptor konsep, programmer, komposer, reporter, dan pembangun.
\end{abstract}

Kata Kunci : Supervisi pendidikan, Mutu Pendidikan

\section{PENDAHULUAN}

Dilihat dari perkembangan teknologi, ilmu pengetahuan serta sosial ekonomi masyarakat, dapat lebih meningkatkan mutu pendidikan termasuk sarana dan prasarana yang diperlukan dalam dunia pendidikan, sesuai dengan perkembangan zaman.

Supervisi dilakukan oleh supervisor dengan melakukan kunjungan kelas. Supervisor memeriksa persiapan guru mengajar dan mengomentari persiapan mengajar yang dibuat oleh guru. Serta mengamati mengajar dan mencatat segala sesuatu yang berkaitan dengan pelaksanaan pembelajaran yang dilakukan oleh guru. Dari supervisor dilakukan dikusi dengan guru, dan memberikan komentar tentang apa aja yang harus di tingkatkan. Biasanya pendekatan supervisi dilakukan sampai tahap memeriksa rencana pembelajaran atau mengamati pelaksanaan pembelajaran yang dilakukan guru di kelas.

\begin{abstract}
Dilihat dari kondisi dunia pendidikan di Indonesia, terutama supervisi yang pengelolaannya masih mempungaruhi mutu pendidikan.
\end{abstract}

Dapat ditelaah bahwa lembaga pendidikan mengalami penurunan mutu yang disebabkan (1)supervisi pendidikan yang tidak dilaksanakan secara profesional, karena pemahaman dan pelaksanaan supervisi yang masih kaku dan sebatas formalitas, yaitu masih adanya jarak antara supervisor dengan guru. (2) keterbatasan sarana dan prasarana yang mengakibatkan pembelajaran tidak maksimal terutama di lembaga pendidikan yang terletak di daerah terutama daerah terpencil. (3) data nasional yang diperoleh dari hasil Ujian Nasional yang pelaksanaannya tidak sepenuhnya dengan kejujuran. (4) Masih banyaknya birokrat di bidang pendidikan yang melakukan korupsi, kolusi, dan nepotisme (KKN).

Berdasarkan uraian di atas, permasalahan dalam tulisan ini adalah 
bagaimana cara meningkatkan mutu pendidikan melalui supervisi salah satunya mengenai sarana dan prasarana dalam mencapai kualitas pendidikan? Dengan tujuan untuk mengetahui cara

\section{PEMBAHASAN}

Seiring dengan perkembangan ilmu pengetahuan, teknologi, serta sosial ekonomi dan budaya masyarakat perkembangan supervisi pendidikan berkembang sebagaimana dikemukakan yaitu supervisi bergerak dari berbentuk inspeksi dimana otoritas lebih didominasi oleh supervisor, berkembang dalam bentuk kolaborasi antara supervisor dan guru bersama berinisiatif dan bertanggungjawab dalam meningkatkan kualitas pembelajaran, serta menumbuhkan budaya belajar pada guru untuk selalu meningkatkan kompetensinya(Sabandi A, 2013).

Supervisi ditujukan kepada penciptaan atau pengembangan situasi belajar mengajar yang lebih baik. Aspek yang perlu diperhatikan yaitu : (1) Pelaksanaan kegiatan belajar mengajar, (2) Hal-hal yang menunjang kegiatan belajar mengajar. Karena aspek utama adalah guru, maka layanan dan aktivitas kesupervisian harus lebih diarahkan kepada upaya memperbaiki dan meningkatkan kemampuan guru dalam mengelola kegiatan belajar mengajar. Guru harus memiliki : 1) kemampuan personal, 2) kemampuan profesional 3) kemampuan sosial".

Supervisi pendidikan adalah bimbingan profesional bagi guru-guru. Yang dimaksud dengan bimbingan profesional yaitu Bimbingan profesional yang dimaksudkan adalah segala usaha yang memberikan kesempatan bagi guruguru untuk berkembang secara profesional, sehingga mereka lebih maju lagi dalam melaksanakan tugas pokoknya, yaitu memperbaiki dan meningkatkan proses belajar siswa. meningkatkan mutu pendidikan melalui supervisi salah satunya mengenai sarana dan prasarana dalam mencapai kualitas pendidikan.

Proses pengawasan/supervisi meliputi dua hal, yaitu menetapkan standar-standar pelaksanaan pekerjaan dan pengukuran hasil/ pelaksanaan pekerjaan.(Ariasa Giri, 2017)

\section{Pendekatan Supervisi}

Sabandi mengatakan " beberapa pendekatan supervisi yang lebih populer dikenal dengan supervisi klinis, pengembangan, dan diferensial. Masing pendekatan tersebut memiliki kekuatan dan

kelemahan.

\section{a. Supervisi Klinis}

Supervisi klinis dikembangkan pertama kali berdasarkan gagasan diagnosis dan perlakuan di

bidang medis oleh Morris Cogan tahun 1950 di sebuah sekolah laboratorium di

Universitas Harvard. Pendekatan ini dipengaruhi oleh teori behavioristik.

\section{b. Supervisi Pengembangan}

Supervisi pengembangan Carl D Glickman yang berbasiskan pada pengembangan seperti Erickson dan Piaget Supervisor yang menggunakan model ini memperlakukan guru sebagai individu yang berada pada berbagai tahap pertumbuhan dan pengembangan. Model ini didasarkan pada asumsi bahwa guru memiliki beragam pengalaman, kemampuan, dan tingkat pengembangan karir yang berbeda.

\section{c. Supervisi Differensial}

Supervisi diferensial adalah salah satu pendekatan terbaru supervisi. Supervisi dipelopori oleh Allan Glatthorn. Menurut (1997: 3) bahwa supervisi diferensial 
merupakan pendekatan supervisi yang menyediakan pilihan jenis supervisi dan evaluasi yang sesuai dengan kebutuhan guru.

\section{Pelatihan}

Pendekatan peningkatan kualitas pembelajaran yang lebih efektif dapat dilakukan melalui peningkatan kompetensi guru yang dilakukan dengan pelatihan.

\section{Pendekatan pelatihan}

Pelatihan peningkatan kompetensi guru dapat dilakukan dengan berbagai bentuk, di antaranya: orientasi, kuliah, bermain peran dan simulasi, metode audiovisual, perluasan pekerjaan, magang, pembelajaran terprogram, pelatihan laboratorium, serta pelatihan kelas dan konferensi".

\section{SIMPULAN}

Berdasarkan pembahasan di atas, dapat disimpulkan bahwa Pengembangan sarana dan prasarana merupakan hal yang penting untuk meningkatkan kualitas pembelajaran. Sebagai penanggung jawab keberhasilan penyelenggaraan pendidikan supervisor dapat melakukan beberapa pendekatan untuk meningkatkan sarana dan prasarana termasuk keprofesionalitasan seorang guru, pendekatan itu antara lain teknik supervisi, budaya organisasi pembelajaran serta pelatihan yang dilakukan kepada guru. Pendekatan ini dilakukan secara direktif, kolaboratif, atau nondirektif dengan
Siti Muriah mengatakan, "pengertian mutu mencakup input, proses, dan out put pendidikan.Mengenai input pendidikan adalah segala sesuatu yang harus tersedia karena dibutuhkan untuk berlangsungnya proses. Kesiapan input sangat diperlukan agar proses dapat berlangsung dengan baik".

Muh. Fitrah mengatakan, "dalam bidang pendidikan, yang dimaksud dengan mutu memiliki pengertian sesuai dengan makna yang terkandung dalam siklus pembelajaran.Secara ringkas dapat disebutkan beberapa kata kunci pengertian mutu, yaitu: sesuai standar, sesuai penggunaan pasar/ pelanggan, sesuai perkembangan kebutuhan, dan sesuai lingkungan globa. Adapun yang dimaksud mutu sesuai dengan standar, yaitu jika salah satu aspek dalam pengelolaan pendidikan itu sesuai dengan standar yang telah ditetapkan."

\section{PENUTUP}

mempertimbangkan komitmen dan pengetahuan konsep yang dimiliki guru. Selain itu, pendekatan budaya organisasi pembelajaran serta pendekatan pelatihan yang diberikan kepada guru.

\section{SARAN}

Diharapkan dengan adanya pendekatan yang diberikan kepada guru akan meningkatkan kualitas pembelajaran yang sudah memiliki sarana dan prasarana yang baik sehingga mutu pendidikan baik dan kualitas pendidikan pun akan semakin baik pula. Dengan demikian prestasi anak juga akan semakin meningkat, karena adanya sarana dan prasarana yang baik dalam meningkatakan mutu pendidikan. 


\section{DAFTAR PUSTAKA}

Muriah, S. (2012). Peran Supervisi dalam Meningkatkan Mutu Pendidikan Islam. Dinamika Ilmu $\quad$ XII (1), 1-15. https://journal.iainsamarinda.ac.id/index.php/dinamika_ilmu/article/view/31

Sabandi, a. (2013). Supervisi Pendidikan Untuk Pengembangan Profesionalitas Guru Berkelanjutan. Pedagogi, Jurnal Ilmiah Ilmu Pendidikan , XIII (2), 1-9. http://ejournal.unp.ac.id/index.php/pedagogi/article/view/4275 